\title{
Degradable starch nanoparticle assisted ethanol precipitation of DNA
}

\author{
Alexander C-F. Ip, Tsung Hao Tsai, Imran Khimji, Po-Jung Jimmy Huang and Juewen Liu* \\ Department of Chemistry and Waterloo Institute for Nanotechnology, University of Waterloo, \\ Waterloo, Ontario, Canada \\ Phone : (+1) 5198884567 ext 38919; Fax : (+1) 5197460435 \\ Email: liujw@uwaterloo.ca
}

\begin{abstract}
Precipitation of DNA from a large volume of aqueous solution is an important step in many molecular biology and analytical chemistry experiments. Currently, this is mainly achieved by ethanol precipitation, where a long-term incubation (usually overnight) at low temperature of -20 to $-80{ }^{\circ} \mathrm{C}$ with high salt concentration is required. This method also requires a large quantity of DNA to form a visible pellet and was tested mainly for double-stranded DNA. To improve DNA precipitation, coprecipitating polymers such as linear polyacrylamide has been used. In this work, we report that starch nanoparticles (SNPs) can achieve convenient DNA precipitation at room temperature with a low salt concentration and short incubation time. This method requires as low as $0.01-0.1 \%$ SNPs and can precipitate both single- and double-stranded DNA of various lengths. The effect of salt concentration, $\mathrm{pH}$ and the crosslinking density of SNPs has been systematically studied. Compared to other types of precipitating agents, SNPs are highly biocompatible and can be degraded by a common enzyme (amylase). This work suggests a novel application of a bio-based material that is prepared in mass production.
\end{abstract}

The final publication is available at Elsevier via http://dx.doi.org/10.1016/j.carbpol.2014.04.007 (C) 2014. This manuscript version is made available under the CC-BY-NC-ND 4.0 license http://creativecommons.org/ licenses/by-nc-nd/4.0/ 


\section{Introduction}

Our understanding on the function of DNA has expanded significantly from simply a carrier of genetic information to catalysts (e.g. DNAzymes) (Breaker \& Joyce, 1994), ligands (e.g. aptamers) (Wilson \& Szostak, 1999), and structural scaffolds in nanotechnology (Pinheiro, Han, Shih \& Yan, 2011; Seeman, 2003; Storhoff \& Mirkin, 1999; Wang, Yang, Yang \& Tan, 2009). DNA oligomers can be synthesized using chemical methods while long DNA sequences are exponentially amplified through polymerase chain reaction (PCR) or extracted from biological sources. To enable many of the DNA-related applications, it is critical to effectively precipitate, concentrate, purify and isolate DNA from a large volume of aqueous sample. Conventional methods for this include ethanol precipitation, ultrafiltration and reverse phase chromatography followed by lyophilization. Ethanol precipitation is a popular choice since it is simple to carry out, where ethanol is added to the DNA in the presence of a high concentration of salt at low temperature. However, the method is limited by the necessity of a large amount of DNA, requiring overnight incubation in sub-zero temperatures. If the concentration of DNA is too low, the precipitant cannot be easily collected since no well-defined pellet can be observed.

To assist in DNA recovery using ethanol precipitation, a co-precipitant is sometimes introduced. Linear polyacrylamide has been commonly used for this purpose while polyethylene glycol and glycogen have also been tested. High recovery efficiency can be achieved with ultra-low temperature incubation (e.g. $-70^{\circ} \mathrm{C}$ ), but it works well only for DNA longer than 30 base pairs (Gaillard \& Strauss, 1990). DNA shorter than 20 base pairs showed very poor recovery. If the reagents are mixed and centrifuged at room temperature, the recovery efficiency is only $\sim 70 \%$ (Fregel, González \& Cabrera, 2010; Tracy, 1981). In addition, commercial samples of glycogen have been found to contain trace amounts of DNA contaminants (Bartram, Poon \& Neufeld, 2009). Linear polyacrylamide is an alternative co-precipitant, but requires additional steps in polymerization, and residual unpolymerized acrylamide may raise toxicity concerns depending on the end use of the DNA. So far, no work has been shown on the precipitation of short single-stranded DNA, which becomes more and more important for 
analytical, biomedical and nanotechnological applications (Famulok, Hartig \& Mayer, 2007; Liu, Cao \& Lu, 2009).

Starch is a naturally occurring polymer of glucose that is abundant with good biocompatibility. The natural granules of starch are typically of many micrometers in size, and various processes have been tested to reduce the size of starch granules into the nanoscale, increasing the surface area and processibility (Le Corre, Bras \& Dufresne, 2010). Some of these processes have already been made in an industrial scale, where multiple tons of nanoparticles are generated in a reactive extrusion process (Bloembergen et al., 2010; Lee, Bloembergen \& van Leeuwen, 2010; Song, Thio \& Deng, 2011; van Ballegooie, Greenall, Bloembergen \& DeJong, 2012). To keep the starch chains together, a crosslinking agent is often used. An effective crosslinker must have at least two sites for reacting with starch; the most commonly available are the hydroxyl groups on the C2, C3, and C6 carbons. Reported crosslinking agents include phosphorus oxychloride (Xiao et al., 2006; Yu, Xiao, Tong, Chen \& Liu, 2007), sodium tripolyphosphate (Li, de Vries, Slaghek, Timmermans, Cohen Stuart \& Norde, 2009; Li, Kleijn, Cohen Stuart, Slaghek, Timmermans \& Norde, 2011; O'Brien, Wang, Vervaet \& Remon, 2009; Simi \& Emilia Abraham, 2007), epichlorohydrin (Bajpai \& Bhanu, 2007; Hamdi, Ponchel \& Duchene, 2001; Likhitkar \& Bajpai, 2012), diepoxybutanes (Simkovic, Hricovini, Mendichi \& Soest, 2004), glyoxal (Uslu \& Polat, 2012), citric acid (Ma, Jian, Chang \& Yu, 2008; Reddy \& Yang, 2010), and dialdehydes (Khachatryan, Khachatryan, Fiedorowicz, Para \& Tomasik, 2013).

Normally, starch is not expected to interact with DNA, since there is no charge attraction or other specific binding mechanisms. In the presence of ethanol, however, starch and DNA might coprecipitate. Herein, we report that DNA can be readily recovered by starch nanoparticles (SNPs) during ethanol precipitation at room temperature with a simple mixing. As a co-precipitation method, it also confers the advantages of a faster precipitation while recovering small concentrations of DNA and the material itself is from a renewable source (Habibi, Lucia \& Rojas, 2010; Sato, Ali, Pelton \& Cranston, 
2012). Finally, SNPs can be easily removed through enzyme degradation and thus minimize potential interference.

\section{Materials and Methods}

2.1. Chemicals. All the single-stranded (ss)-DNA samples were purchased from Integrated DNA Technologies (Coralville, IA). The double-stranded (ds)-DNA ladder was from New England Biolabs. Four different types of research grade SNPs were supplied by EcoSynthetix Inc. (Burlington, Ontario, Canada). The SNPs are internally crosslinked produced via a reactive extrusion process where the crosslinker content was $0,1,3$, and $5 \%(w / w)$. The crosslinker used to produce these 4 research grade samples was glyoxal. $\mathrm{NaBr}, 2,2,6,6$-Tetramethyl-1-piperidinyloxy (TEMPO), (5\% NaClO, bleach), and amylase from porcine pancreas were from Sigma-Aldrich. N-(2-hydroxyethyl)piperazine- $\mathrm{N}^{\prime}-(2-$ ethanesulfonic acid) (HEPES), 2-(N-morpholino)ethanesulfonic acid (MES) and $\mathrm{NaCl}$ were from Mandel Scientific (Guelph, ON, Canada).

2.2. SNP oxidation. The oxidation of SNPs typically follows the protocol as described previously in literature (Kato, Matsuo \& Isogai, 2003). TEMPO acts as a catalyst to oxidize the primary hydroxyl group in the glucose unit of SNPs into a carboxyl group. In brief, a $5 \% \mathrm{w} / \mathrm{w}$ dispersion of SNPs is oxidized through a TEMPO-catalyzed reaction at under $5{ }^{\circ} \mathrm{C}$ using an ice-water bath. Bleach was added to oxidize up to $20 \%$ of available glucose units, with $0.5 \mathrm{M} \mathrm{NaOH}$ added to maintain $\mathrm{pH}$ above 10. The level of oxidation was determined based on the amount of $\mathrm{NaOH}$ used to reach a final of neutral $\mathrm{pH}$. Afterwards, oxidized SNPs were purified through ethanol precipitation and centrifugation.

2.3. DNA precipitation. Starch solutions were prepared by dissolving SNPs in Milli-Q water to give a $10 \%(\mathrm{w} / \mathrm{v})$ stock concentration. These solutions were further diluted to $1 \%(\mathrm{w} / \mathrm{v})$ working concentrations. 6-carboxyfluorescein (FAM)-labeled DNAs (50 $\mu \mathrm{M}$ working concentrations) were prepared in $100 \mathrm{mM}$ buffer (HEPES, $\mathrm{pH}$ 7.6). The SNP mixture and DNA solution were brought together with a $50 \mathrm{mM} \mathrm{NaCl}$ buffer in a 1:1:8 volumetric ratio and allowed to incubate at $20{ }^{\circ} \mathrm{C}$ for $1 \mathrm{~h}$. Afterwards, ethanol or Milli-Q water was added at twice the volume and centrifuged for 20 min at 
$22000 \mathrm{G}$ at $20{ }^{\circ} \mathrm{C}$. Fluorescence measurements were performed using a plate reader by removing $5 \mu \mathrm{L}$ of the supernatant and added to $95 \mu \mathrm{L}$ of $50 \mathrm{mM}$ HEPES buffer.

SNP dispersions were prepared at $10 \% \mathrm{w} / \mathrm{v}$ in Milli-Q water. Serial dilutions of 1:10 were sequentially prepared for lower concentrations. Buffer solutions were prepared with $50 \mathrm{mM}$ MES and $50 \mathrm{mM} \mathrm{NaCl}$ at $\mathrm{pH}$ 6.0. DNA and starch mixtures were prepared by mixing $2 \mu \mathrm{L}$ DNA solution, $2 \mu \mathrm{L}$ starch dispersion, and $16 \mu \mathrm{L} \mathrm{MES/NaCl} \mathrm{buffer.} \mathrm{For} \mathrm{larger} \mathrm{volumes} \mathrm{needed} \mathrm{for} \mathrm{digital} \mathrm{photography,}$ volumes were scaled up accordingly. The mixture was briefly vortexed and then allowed to incubate in ambient temperature away from light for $60 \mathrm{~min}$. Precipitation of DNA was performed by adding twice the solution volume of ethanol and centrifuged at $21000 \mathrm{RCF}$ for $30 \mathrm{~min}$. For fluorescence readings, 5 $\mu \mathrm{L}$ was removed from the supernatant and added to $95 \mu \mathrm{L}$ of $50 \mathrm{mM}$ HEPES in a 96-well plate. Fluorescence readings were performed on a SpectraMax M3 from Molecular Devices, LLC (Sunnyvale, California) at $485 \mathrm{~nm}$ excitation and $525 \mathrm{~nm}$ emission. Each sample was repeated four times.

2.4. Gel electrophoresis. Polyacrylamide gel electrophoresis was performed on a ds-DNA ladder ranging from $25-766$ bp using a $15 \%$ acrylamide/bis-acrylamide gel. Electrophoresis of the ds-DNA ladder was prepared having the ladder proceed through the precipitation protocol described above. The supernatant was separated from the pelletized starch/adsorbed DNA, and the pellet re-suspended in 20 $\mu \mathrm{L} 50 \mathrm{mM}$ HEPES. The re-suspended pellet and $20 \mu \mathrm{L}$ of the supernatant were each mixed with $20 \mu \mathrm{L}$ of $30 \% \mathrm{w} / \mathrm{w}$ of glycerol and loaded into their respective loading wells within the polyacrylamide gel. The gel electrophoresis was performed at $600 \mathrm{~V}$ and $100 \mathrm{~mA}$ for 90 minutes. The resultant DNA migration inside the gel was stained with $0.5 \mu \mathrm{g} / \mathrm{mL}$ of ethidium bromide for $30 \mathrm{~min}$, and then imaged under $302 \mathrm{~nm}$ fluorescence excitation.

2.5. Amylase assay. Digestion of starch by amylase was carried out similar to the precipitation protocol described above; the major change is the addition of $5 \mu \mathrm{L}$ of $2 \mathrm{mg} / \mathrm{mL}$ amylase after incubation of $1 \mathrm{~h}$ in ambient conditions. The amylase was allowed to incubate for an additional hour at $37^{\circ} \mathrm{C}$ before the addition of ethanol and subsequent centrifugation. 
2.6. DLS. DLS measurements were performed on a Malvern Zetasizer Nano ZS90 at $25^{\circ} \mathrm{C}$. Averages of 3 runs were made, each run consisting of 10 measurements for 1 min each. Concentrations of $0.05 \%$ w/v SNPs were used.

\section{Results and Discussion}

3.1. Characterization of SNPs. Our internally crosslinked SNPs were made by reactive extrusion in an industrial scale. The $\zeta$-potential the SNP was close to zero and the particles are believed to be stabilized via steric effects of the pendant sugar chains (Figure 1A). The surface of the SNPs is rich in hydroxyl groups. The hydrodynamic size of the SNPs was $\sim 25 \mathrm{~nm}$ as determined by dynamic light scattering (DLS, Figure 2A).

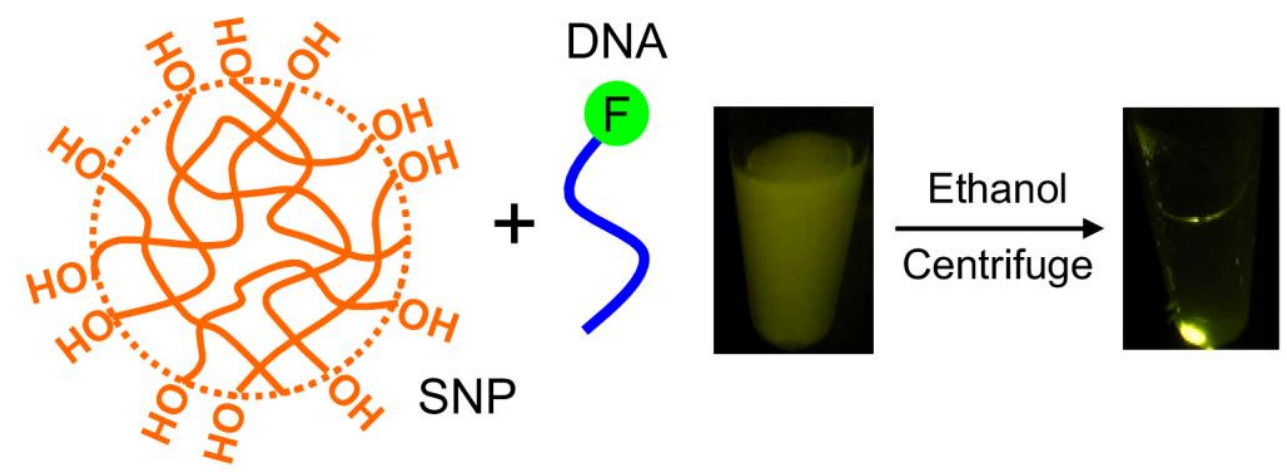

Figure 1. Schematics of DNA precipitation with SNP in ethanol. Photographs of DNA dispersed in water and after SNP-assisted precipitation are also shown.

3.2. Effect of charge on SNPs. Since it is quite difficult to precipitate short DNA, to test whether SNPs can address this problem, we first employed a 12-mer DNA with a 6-carboxyfluorescein (FAM) label (DNA1, FAM-CACTGACCTGGG-3') to follow DNA adsorption based on fluorescence. Sample solutions were prepared by dissolving these SNPs in water to give a $10 \%(\mathrm{w} / \mathrm{v})$ concentration. As an initial test, DNA1 in $100 \mathrm{mM}$ HEPES was mixed with a final of $0.1 \%$ SNP. To probe the electrostatic 
effect, we further oxidized the SNPs using TEMPO-mediated oxidation to generate carboxyl groups (i.e. negative charges) (Kato, Matsuo \& Isogai, 2003). This oxidation procedure was allowed to proceed to oxidize $20 \%$ of the available C6 carbons within the starch chains. To this mixture, ethanol of double volume was added (e.g. final $\sim 67 \%$ ethanol) and the samples were centrifuged. As shown in Figure 2B, the sample without SNP did not show much precipitation since the sample was not cooled to low temperature and the salt concentration was very low. Note that low temperature and high salt are the required conditions for normal ethanol precipitation protocols. The SNP sample produced a welldefined pellet with strong green fluorescence, indicating precipitated DNA. The oxidized SNPs with negative charge showed more background fluorescence in solution, possibly due to the electrostatic repulsion between DNA and the starch chains. Therefore SNPs without oxidation is a better formulation for precipitating DNA. For quantitative measurement, the supernatant was diluted 20 times in buffer (50 mM HEPES, pH 7.6), where its fluorescence intensity indicates the amount of nonprecipitated DNA. This fluorescence was compared with DNA in water and with ethanol alone as precipitating agent (Figure 2D). About $90 \%$ of the DNA was precipitated by SNPs, while ethanol alone showed no obvious DNA precipitation. Carboxyl modified SNPs showed less than 50\% DNA precipitation, consistent with the electrostatic repulsion with DNA. We further studied the level of SNP oxidation (Figure 2C), where a significant decrease in DNA precipitation was observed at greater than $10 \%$ oxidation. 

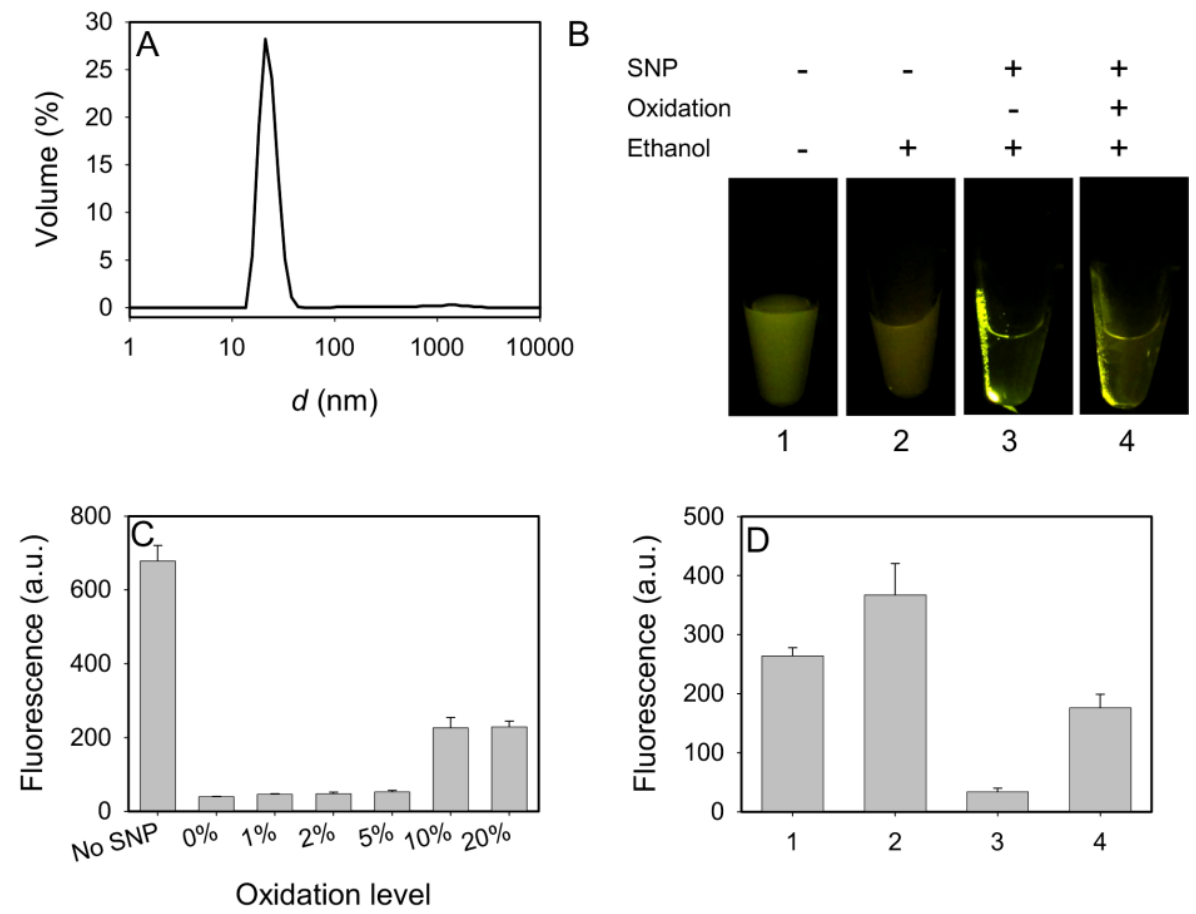

Figure 2. (A) A DLS spectrum of a typical SNP sample used in this work (non-crosslinked). (B) Photographs of DNA precipitated under various conditions. Oxidation means carboxyl modified SNPs. (C) DNA precipitation measured as a function of SNP oxidation level. A lower fluorescence intensity means more precipitated DNA. (D) Supernatant fluorescence intensity of the samples in (A) indicating non-precipitated DNA concentration. The ethanol concentration was $67 \%$ in this experiment.

3.3. Effect of crosslinking density and alcohol concentration. Our SNPs were stabilized by internal chemical crosslinkers and crosslinking density might affect precipitation efficiency. Changing the crosslinking density might also provide mechanistic insights. Next we employed SNPs with 0 to $5 \%$ crosslinkers (Figure 3A). In addition, we also varied the concentration of SNPs. When the concentration of SNPs is high, all the samples showed similar capability of precipitating DNA, where more than 90\% DNA was recovered. At lower SNP concentrations (e.g. below 0.01\%), lower crosslinking density appears to be slightly more efficient for precipitating DNA, which might be related to a higher porosity and more effective DNA penetration into the core of the particles (Bloembergen et 
al., 2010). In this regard, DNA was used as a probe for the internal structure of SNPs. Our DNA concentration was $5 \mu \mathrm{M}$ or $0.002 \%$, where notable recovery $(\sim 80 \%)$ was observed at $0.01 \%$ SNP concentration. Based on their similar mass we can deduce that most of the SNP chains were effectively utilized. For comparison, polyacrylamide is often used between $0.025-0.25 \%$ to precipitate DNA, which is in the similar range as our SNPs. We further varied the concentration of ethanol and also tested isopropanol (Figure 3B). It is interesting to note that no DNA precipitation was achieved at below 50\% alcohol concentrations. Moderate precipitation was observed at $60 \%$, where isopropanol appeared to be slightly more effective. At 70 or $80 \%$, more than $90 \%$ DNA was precipitated with little difference observed between these two alcohols. The property of DNA is changed quite drastically when the concentration of ethanol is more than $60 \%$ (e.g. dehydration and conformational changes) (Piskur \& Rupprecht, 1995), and this is likely to be the reason for the observed DNA co-precipitation. We chose to use ethanol for the rest of the study since it is a more commonly used reagent.
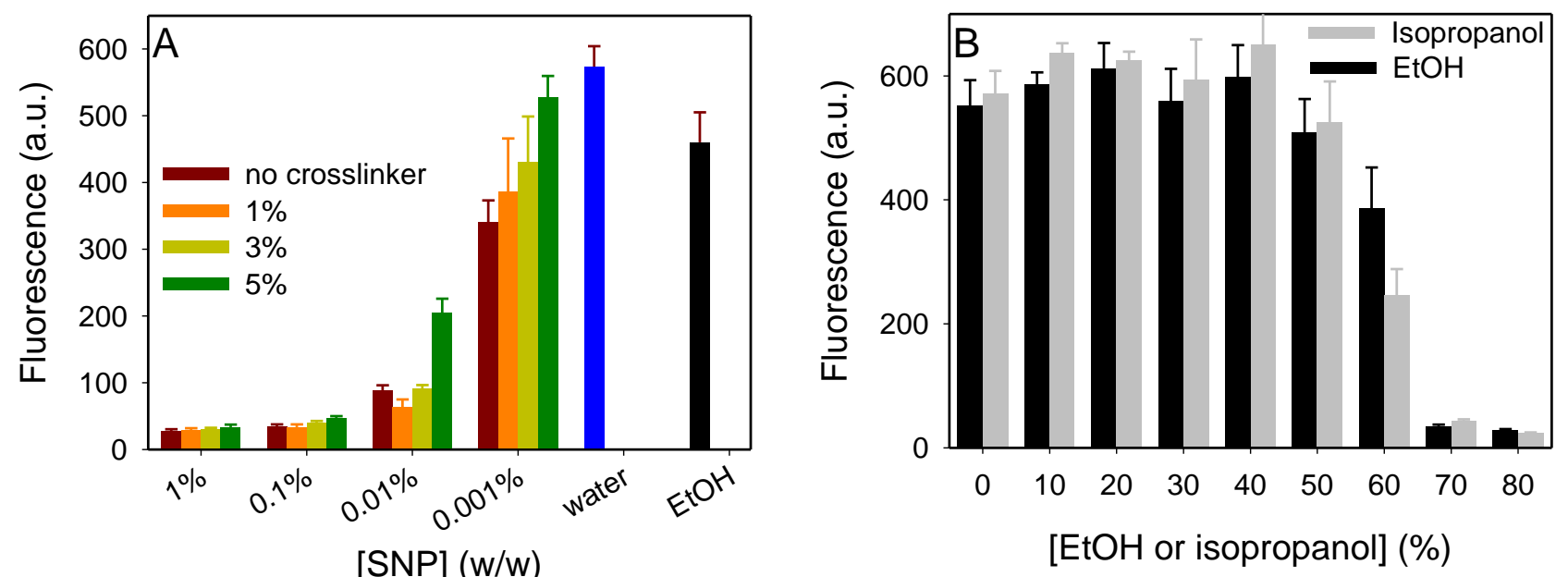

[EtOH or isopropanol] (\%)

Figure 3. (A) The effect of SNP crosslinking density and concentration on DNA precipitation determined by the supernatant fluorescence. The last two bars are control of free DNA in water and precipitation with ethanol alone without SNPs. (B) Effect of alcohol concentration on DNA precipitation. 
3.4. Effect of DNA length and sequence. Most previous work focused on ds-DNA, where the sequence of DNA should have little effect. We tested ss-DNA in this study, and the sequence of DNA might be important. To systematically understand it, FAM-labeled poly-A, poly-T, poly-C and poly-G of 15 bases were tested (Figure 4A). The initial fluorescence of the poly-G DNA is much lower than the rest due to the fluorescence quenching properties of guanine. All the sequences show a low fluorescence signal after precipitation in ethanol and centrifugation. However, poly-G DNA showed only $\sim 50 \%$ fluorescence decrease, suggesting that this DNA might not bind to SNPs very effectively in ethanol. Poly-G DNA is known to form quadruplex structures and it may shield the bases needed for binding to SNPs in ethanol. It is interesting to note that similar efficiency of precipitation was observed when $\mathrm{G}_{15}$ was dispersed in ethanol alone. Therefore, the SNPs might not provide additional precipitation power for guanine polymers. Next, poly-A DNA with 15, 30, 45, and 90 bases were used for co-precipitation with the SNPs and all the sequences were precipitated by more than 90\% (Figure 4B). Therefore, as long as the DNA is not a homopolymer of guanine, SNPs can be an effective coprecipitation agent.
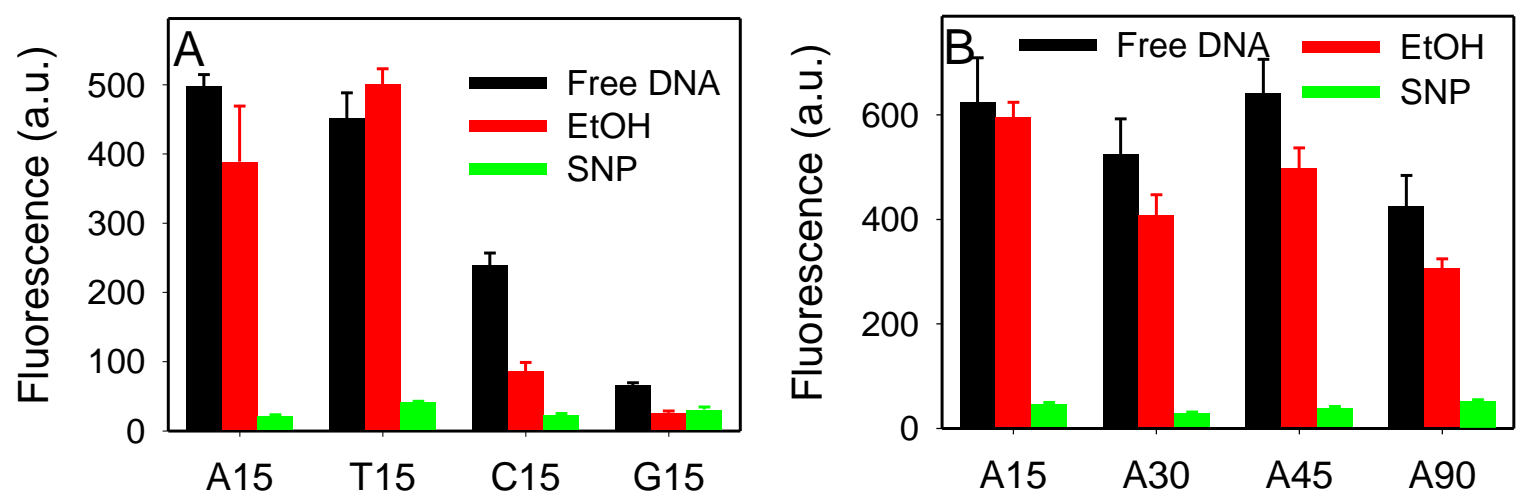

Figure 4. Effect of DNA nucleotide composition (A) and length (B) on supernatant fluorescence after DNA precipitation. 
3.5. Effect of salt and $\mathbf{p H}$. Since salt concentration is an important parameter for traditional ethanol precipitation, we next tested SNP-assisted DNA precipitation using different amounts of salt. Figure 5A shows that adding $\mathrm{Mg}^{2+}$ can slightly improve the efficiency of DNA precipitation but the effect of salt is not very obvious with up to $100 \mathrm{mM} \mathrm{Mg}^{2+}$, all showed high DNA recovery. At the same time, $\mathrm{pH}$ does not affect the precipitation either and highly efficient DNA precipitation was achieved from pH 3 to $\mathrm{pH} 9$ (Figure 5B). The same conclusions were reached when a lower SNP concentration $(0.05 \%)$ was used to study the effect of salt and $\mathrm{pH}$ (see Supporting Information). This study also indicates that the interaction between DNA and SNPs in ethanol is not dependent on ionic strength or $\mathrm{pH}$. Most likely, DNA has low solubility in ethanol since it is highly charged and SNPs also have low solubility since it is very hydrophilic. The interaction between DNA and SNPs becomes favorable in ethanol.
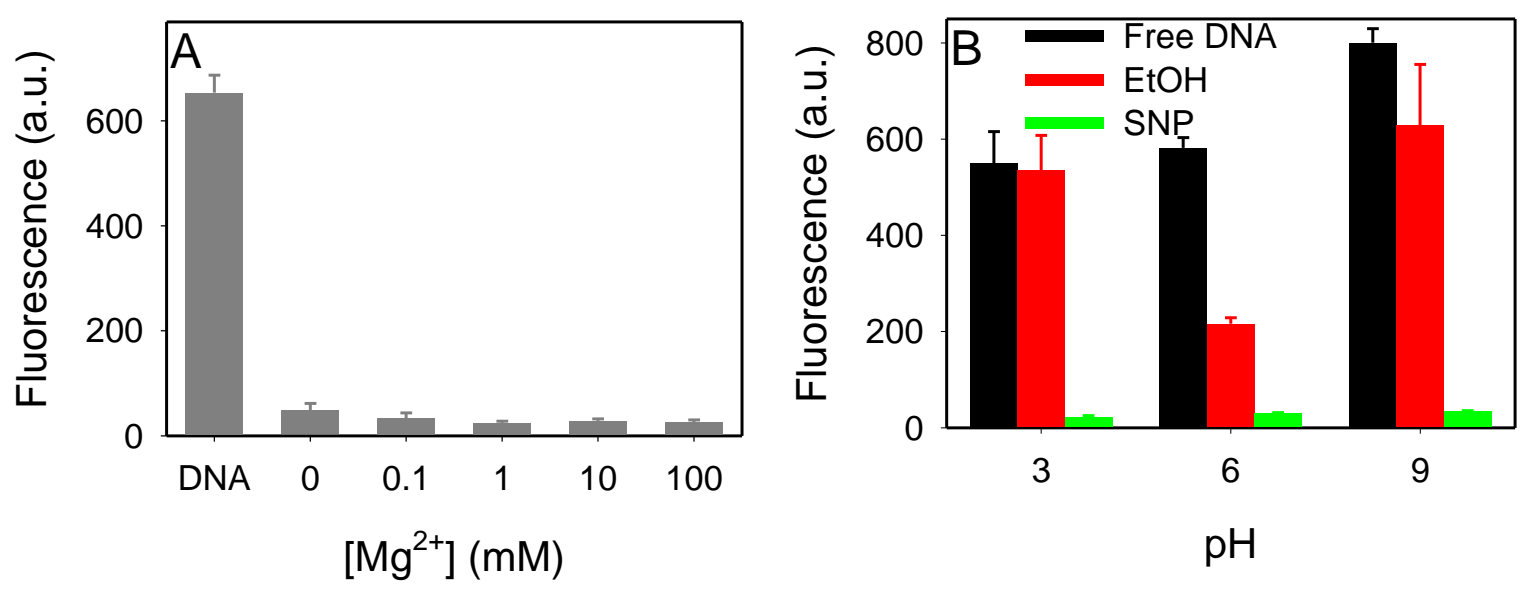

Figure 5. Effect of salt concentration (A) and $\mathrm{pH}$ (B) on DNA precipitation by SNPs.

3.6. Precipitating ds-DNA. Our work presented above has focused on ss-DNA. Next we tested a dsDNA ladder from $25 \mathrm{bp}$ to $766 \mathrm{bp}$ (lane 2). With ethanol alone, we observed that the precipitant contained mainly high MW DNA (lane 1) while the supernatant contained low MW DNA (lane 4). 
With SNP-assisted precipitation, all the DNA are in the pellet (lane 3) and no DNA was observed in the supernatant (lane 5). This experiment indicates that the SNPs can also be applied to precipitate ds-DNA with a diverse range of lengths.

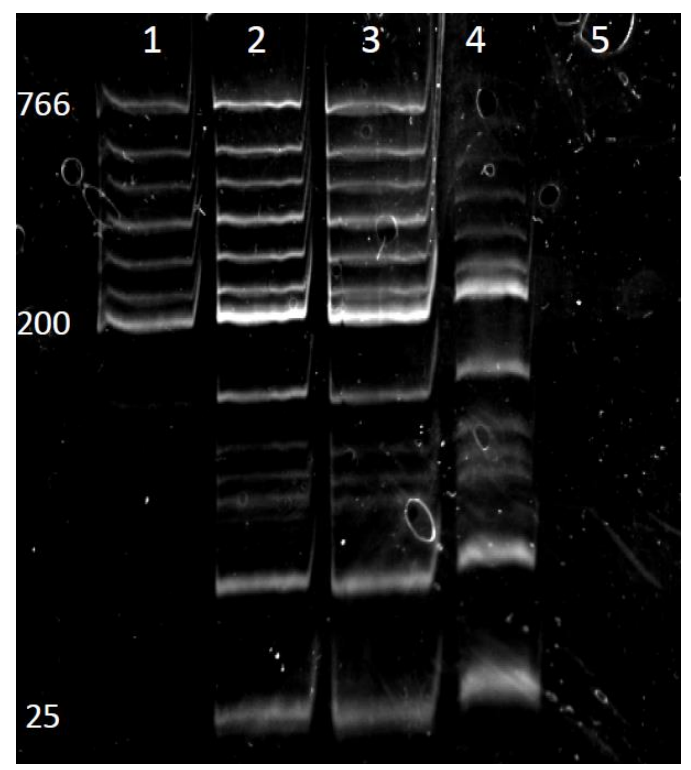

Figure 6. A photograph of non-denaturing gel loaded with DNA samples from supernatant or resuspended pellet after precipitation under various conditions. Lane 1: pellet from ethanol precipitation; lane 2: free DNA ladder; lane 3: pellet from SNP-assisted precipitation; lane 4: supernatant after ethanol precipitation; lane 5: supernatant after SNP-assisted precipitation.

3.7. Removal of starch by amylase. Compared to other types of precipitation agents, a unique feature of SNPs is that they can be degraded by enzymatic degradation, while it is more difficult to degrade polymers such as linear polyacrylamide. To test this, we took a precipitated sample and treated it with iodine to produce a blue color based on the well-known $\mathrm{I}_{2} /$ starch interaction. The samples showed an intense blue color (Figure 7A, red spectrum), indicating that the helical structure of starch is at least 
partially retained in SNPs. After the amylase treatment, the purple color was significantly reduced as confirmed by the UV-vis spectroscopic measurement (Figure 7A, black spectrum). Therefore, the SNPs can still be degraded by the enzyme and the internal crosslinks do not hinder the enzymatic reaction. This is also reflected in the ability of the SNPs to precipitate DNA, where after the enzyme treatment, the samples cannot precipitate DNA (Figure 7B).

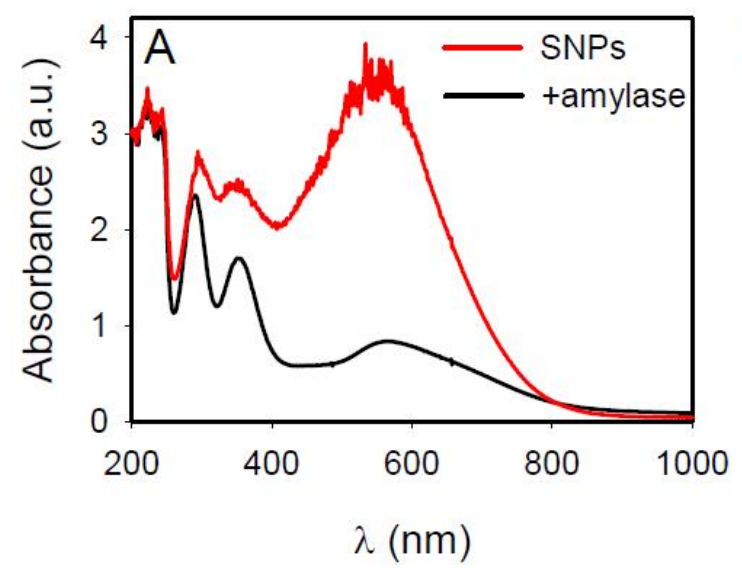

B

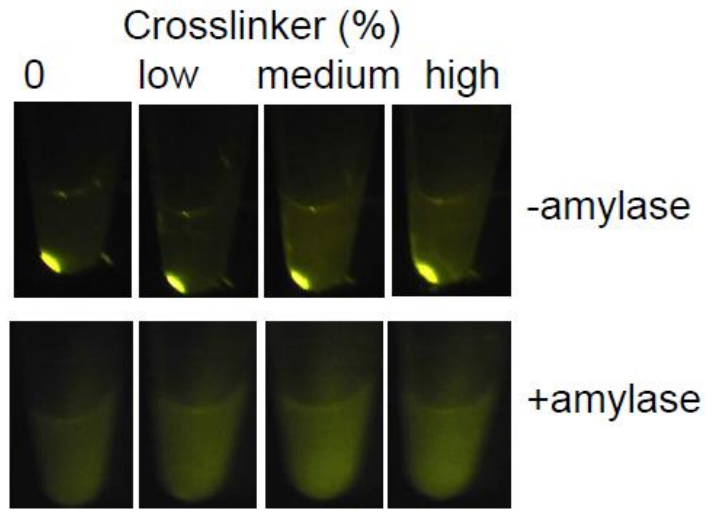

Figure 7. (A) UV-vis spectra showing degradation of SNPs by amylase. (B) Photographs of DNA precipitation by SNPs of various crosslinking density before and after amylase treatment.

\section{Conclusions.}

In summary, we described a simple, cost-effective and efficient method for precipitating DNA using ethanol and SNPs. Under the mild conditions used in this study (e.g. room temperature, low salt and short incubation time), SNPs can help achieve greater than $90 \%$ recovery efficiency, while ethanol alone often showed no recovery, especially for short ss-DNA. We systematically studied the effect of DNA length, sequences, ss- and ds-DNA, $\mathrm{pH}$ and salt concentration. On the SNP side, we also tested the effect of surface charge and internal crosslinking density. Compared to other polymer coprecipitation agent, SNPs are unique in terms of its good biocompatibility and can be degraded by 
adding a simple enzyme, amylase. Finally, SNPs are from renewable bio-based materials and this work represents a novel application of such materials in biotechnology.

\section{Appendix A. Supplementary data}

\section{Acknowledgments}

We thank Dr. Steven Bloembergen for helpful discussions and EcoSynthetix Inc. for providing the SNP samples. Funding for this project is from the NSERC and EcoSynthetix Inc. through a collaborative research and development $(\mathrm{CRD})$ grant.

\section{References.}

1) Bajpai, A. K., \& Bhanu, S. (2007). Dynamics of controlled release of heparin from swellable crosslinked starch microspheres. J. Mater. Sci-Mater. M., 18, 1613-1621.

2) Bartram, A. K., Poon, C., \& Neufeld, J. D. (2009). Nucleic acid contamination of glycogen used in nucleic acid precipitation and assessment of linear polyacrylamide as an alternative coprecipitant. BioTechniques, 47, 1016-1019.

3) Bloembergen, S., Vanegdom, E., Wildi, R., McLennan, I. J., Lee, D. I., Klass, C. P., \& Van Leeuwen, J. (2010). Biolatex binders for paper and paperboard applications. J. Pulp Pap. Sci., $36,151-161$.

4) Breaker, R. R., \& Joyce, G. F. (1994). A DNA enzyme that cleaves rna. Chem. Biol., 1, 223-229.

5) Famulok, M., Hartig, J. S., \& Mayer, G. (2007). Functional aptamers and aptazymes in biotechnology, diagnostics, and therapy. Chem. Rev., 107, 3715-3743.

6) Fregel, R., González, A., \& Cabrera, V. M. (2010). Improved ethanol precipitation of DNA. Electrophoresis, 31, 1350-1352. 
7) Gaillard, C., \& Strauss, F. (1990). Ethanol precipitation of DNA with linear polyacrylamide as carrier. Nucleic Acids Res., 18, 378-378.

8) Habibi, Y., Lucia, L. A., \& Rojas, O. J. (2010). Cellulose nanocrystals: Chemistry, selfassembly, and applications. Chem. Rev., 110, 3479-3500.

9) Hamdi, G., Ponchel, G., \& Duchene, D. (2001). Formulation of epichlorohydrin cross-linked starch microspheres. J. Microencapsul., 18, 373-383.

10) Kato, Y., Matsuo, R., \& Isogai, A. (2003). Oxidation process of water-soluble starch in tempomediated system. Carbohyd. Polym., 51, 69-75.

11) Khachatryan, K., Khachatryan, G., Fiedorowicz, M., Para, A., \& Tomasik, P. (2013). Formation of nanometal particles in the dialdehyde starch matrix. Carbohyd. Polym., 98, 568-573.

12) Le Corre, D., Bras, J., \& Dufresne, A. (2010). Starch nanoparticles: A review. Biomacromolecules, 11, 1139-1153.

13) Lee, D. I., Bloembergen, S., \& van Leeuwen, J. (2010). Development of new biobased emulsion binders. TAPPI, PaperCon2010. Atlanta, GA.

14) Li, Y., de Vries, R., Slaghek, T., Timmermans, J., Cohen Stuart, M. A., \& Norde, W. (2009). Preparation and characterization of oxidized starch polymer microgels for encapsulation and controlled release of functional ingredients. Biomacromolecules, 10, 1931-1938.

15) Li, Y., Kleijn, J. M., Cohen Stuart, M. A., Slaghek, T., Timmermans, J., \& Norde, W. (2011). Mobility of lysozyme inside oxidized starch polymer microgels. Soft Matter, 7, 1926-1935.

16) Likhitkar, S., \& Bajpai, A. K. (2012). Magnetically controlled release of cisplatin from superparamagnetic starch nanoparticles. Carbohyd. Polym., 87, 300-308.

17) Liu, J., Cao, Z., \& Lu, Y. (2009). Functional nucleic acid sensors. Chem. Rev., 109, 1948-1998.

18) Ma, X., Jian, R., Chang, P. R., \& Yu, J. (2008). Fabrication and characterization of citric acidmodified starch nanoparticles/plasticized-starch composites. Biomacromolecules, 9, 3314-3320. 
19) O'Brien, S., Wang, Y.-J., Vervaet, C., \& Remon, J. P. (2009). Starch phosphates prepared by reactive extrusion as a sustained release agent. Carbohyd. Polym., 76, 557-566.

20) Pinheiro, A. V., Han, D., Shih, W. M., \& Yan, H. (2011). Challenges and opportunities for structural DNA nanotechnology. Nat Nano, 6, 763-772.

21) Piskur, J., \& Rupprecht, A. (1995). Aggregated DNA in ethanol solution. FEBS Lett., 375, 174178.

22) Reddy, N., \& Yang, Y. (2010). Citric acid cross-linking of starch films. Food Chem., 118, $702-$ 711.

23) Sato, T., Ali, M. M., Pelton, R., \& Cranston, E. D. (2012). DNA stickers promote polymer adsorption onto cellulose. Biomacromolecules, 13, 3173-3180.

24) Seeman, N. C. (2003). DNA in a material world. Nature, 421, 427-431.

25) Simi, C., \& Emilia Abraham, T. (2007). Hydrophobic grafted and cross-linked starch nanoparticles for drug delivery. Bioprocess and Biosystems Engineering, 30, 173-180.

26) Simkovic, I., Hricovini, M., Mendichi, R., \& Soest, J. J. G. v. (2004). Cross-linking of starch with 1,2,3,4-diepoxybutane or 1,2,7,8-diepoxyoctane. Carbohyd. Polym., 55, 299-305.

27) Song, D., Thio, Y. S., \& Deng, Y. (2011). Starch nanoparticle formation via reactive extrusion and related mechanism study. Carbohyd. Polym., 85, 208-214.

28) Storhoff, J. J., \& Mirkin, C. A. (1999). Programmed materials synthesis with DNA. Chem. Rev., 99, 1849-1862.

29) Tracy, S. (1981). Improved rapid methodology for the isolation of nucleic-acids from agarose gels. Preparative Biochemistry, 11, 251-268.

30) Uslu, M.-K., \& Polat, S. (2012). Effects of glyoxal cross-linking on baked starch foam. Carbohyd. Polym., 87, 1994-1999. 
31) van Ballegooie, P., Greenall, P., Bloembergen, S., \& DeJong, R. (2012). Ecosphere® biolatex® binders: Next generation solutions for today's paper coating industry. World Pulp \& Paper (p. 100).

32) Wang, H., Yang, R. H., Yang, L., \& Tan, W. H. (2009). Nucleic acid conjugated nanomaterials for enhanced molecular recognition. ACS Nano, 3, 2451-2460.

33) Wilson, D. S., \& Szostak, J. W. (1999). In vitro selection of functional nucleic acids. Annu. Rev. Biochem., 68, 611-647.

34) Xiao, S. Y., Tong, C. Y., Liu, X. M., Yu, D. M., Liu, Q. L., Xue, C. G., Tang, D. Y., \& Zhao, L. J. (2006). Preparation of folate-conjugated starch nanoparticles and its application to tumortargeted drug delivery vector. Chin. Sci. Bull., 51, 1693-1697.

35) Yu, D., Xiao, S., Tong, C., Chen, L., \& Liu, X. (2007). Dialdehyde starch nanoparticles: Preparation and application in drug carrier. Chin. Sci. Bull., 52, 2913-2918. 